\title{
A Review of Torque Ripple Control Strategies of Switched Reluctance Motor
}

\author{
Xudong Gao ${ }^{1,2}$, Xudong Wang ${ }^{1}$, Zhongyu $\mathrm{Li}^{1}$ and Yongqin Zhou ${ }^{1}$ \\ 1. Harbin University of Science and Technology, Harbin, 150080, P.R. China \\ 2. Heilongjiang Institute of Technology, Harbin, 150050, P.R. China \\ gaoxd1973@163.com
}

\begin{abstract}
Switched reluctance motor is a new type of AC speed-adjustable system with high application value; it has lots of advantages such as simple structure, consistence and durability, low cost, wide speed range and prominent fault-tolerant ability. However, it also has obvious defects such as torque ripple and vibrating noise. By researching the related references at home and abroad, the mechanism, advantages and disadvantages of those control strategies are introduced and analyzed detailed in this article, moreover, the future trend of development in the research direction is also prospected.
\end{abstract}

Keywords: switched reluctance motor; torque ripple; vibration and noise; control strategies

\section{Introduction}

With the rapid development of power electronics, microcomputer and control technology, switched reluctance motor is a new type of speed control driving system developed in the early 80s. Switched reluctance motor speed control system has the following prominent features: simple structure and durable properties, the motor is able to work at an extremely fast speed. The losses mainly produced in the stator resulting in better motor cooling. Permanent magnet is absent in the rotor, permitting a high temperature rise. Torque direction has nothing to do with the current direction, which can simplify the power converter maximally and reduce the cost of the system. Power converter is of high reliability for it does not have short circuit fault. With big starting torque and excellent speed controlling performance, there is no impact of the current in the induction motors at the time of starting. Wide speed range, flexible control, and speedtorque characteristic make it easier to meet various demands. It has high efficiency in the wide speed and power range. With 4 qs moment, it possesses stronger regenerative braking capability [1].

However, due to its own rotor doubly salient structure and switching power supply, torque ripple is large and the noise and vibration are obvious. All these defects limit the application of the switched reluctance motor in some circumstances. Aiming at this obvious shortcoming--Switched reluctance motor torque ripple, combined with the research of related literature at home and abroad, the author of this article analyzes, compares and summarizes the control methods and strategies to lower switched reluctance motor torque ripple.

\section{The Generation Mechanism of Torque Ripple}

According to the principle of magnetic co energy [2], the rotor position at any one phase winding of the magnetic resistance torque formula is as follows: 


$$
T(\theta, i)=\frac{\partial W^{\prime}(\theta, i)}{\partial \theta}
$$

Where $\theta$ is rotor azimuth; $i$ is phase current; $W^{\prime}(\theta, i)$ is total magnetic energy, Defined as the area under the curve of magnetization shown in Fig 1, it can be expressed as: $W^{\prime}(\theta, i)=\int_{0}^{i} \psi(\theta, i) d i W^{\prime}$.

In certain cases the switch reluctance motor is not affected by the influence of magnetic saturation and inductance has nothing to do with the phase current. Due to the $\psi(\theta, i)$ can be expressed as $\psi(\theta, i)=L(\theta, i) i$, Therefore, the torque generated as:

$$
T(\theta, i)=\frac{1}{2} \frac{\partial}{\partial \theta} \int_{0}^{i^{2}} L(\theta, i) d i^{2}
$$

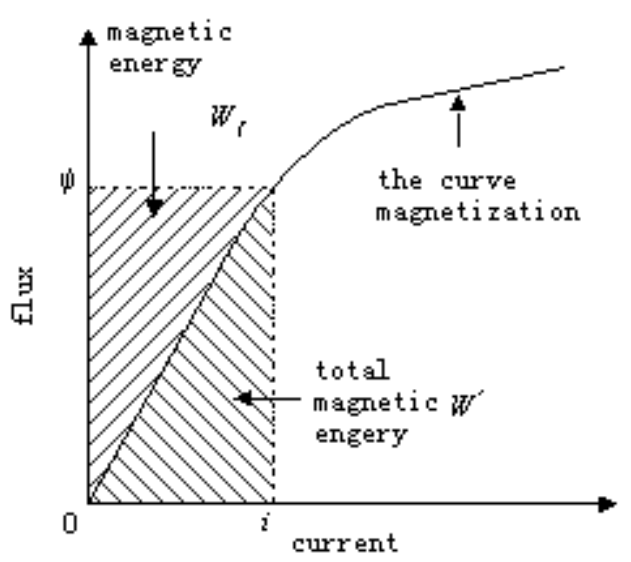

Figure 1. The Sketch Graph of Magnetic co Energy

In each phase winding constant current situation, the motor rotor moment by changing tangential electromagnetic force and the role of radial electromagnetic force, pulsating tangential magnetic suction will produce electromagnetic torque of SRM operation. Switched reluctance motor torque ripple is more complex, there are many factors. It is mainly involved: doubly salient structure of the motor body; distribution with severe nonlinearity; nonlinear effects of structural parameters, and so on. In order to maintain the continuous operation of switched reluctance motor must be constantly switching power converter main switching devices and provide the same direction of electromagnetic forces. Switching circuit provides pulse current that will produce the magnetic field of step and form torque ripple. Inverter circuit for the motor power supply, in addition to the fundamental voltage of the stator, there are a series of harmonic components, which leading to fluctuations in the stator voltage. Based on the presence of many objective factors, led to a switched reluctance motor torque ripple becomes a significant one of its shortcomings, but also as a long-term research focus of the industry.

\section{Torque Ripple Minimization Methods of SRM}

Switch reluctance motor torque ripple is more complicated and affected by many factor. The different control strategies have different influence rotating torque ripple. Therefore, In the case of definite motor structure and parameters, by selecting proper control strategy can effectively reduce the torque ripple. Here, we present a comparative analysis of domestic and foreign achievements concerning switched reluctance motor torque ripple control strategies. 


\subsection{Traditional Control Strategy}

Typical traditional control in three ways: angular position control (APC), current chopping control (CCC) and voltage chopping control (CVC).

The angular position of the control means at a certain voltage across the winding provided by changing $\theta_{o n}$ and $\theta_{\text {off }}$ of main switch to change power-on and power-off, thereby regulating the phase current waveforms for closed-loop speed control. Opening angle $\theta$ on and off angle $\theta_{\text {off }}$ can be adjusted, so the presence of three combinations adjustment method. In actual control, often taking fixed $\theta_{\text {off }}$ change $\theta_{\text {on }}$ control mode. Because of an item $\theta_{\text {on }}$ and $\theta_{\text {off }}$ will not only affect the phase current waveform, but also affect the adjacent two phase current waveform ,Therefore, the items of $\theta_{\text {on }}$ and $\theta_{\text {off }}$ must be adjusted separately, SRM able to achieve optimum operating angle position control (APC) mode. The main features of the control include: greater torque adjustment range; multi-phase windings are energized simultaneously control; high motor efficiency; suitable for higher speeds but not suitable for low-speed operation.

Current chopping control is mainly for motor running at low speed. Because the phase current is increased rapidly in order to avoid damage from current pulse that needs to limit the peak of current, thereby, obtain the mechanical properties of the constant torque, because this control method rarely involves $\theta_{\text {on }}$ and $\theta_{\text {off }}$ control, so select the position of each phase winding's conduction to control the current by chopper. The control idea is: the phase I comparing with current chopping limited $i_{\text {chop }}$, during the current conduction, if $i<i_{\text {chop }}$ that main switch conduction when phase current rise and gradually reach the chopper limit. If $i>i_{\text {chop }}$, The master switch is shut off and phase current decline, So again, to achieve the phase current small-scale fluctuations in the vicinity of the current chopping limit $i_{\text {chop }}$. The main features of the control include: simple and direct, controlled better; torque smoothly; suitable for low-speed operation of the motor and brake; suitable for torque adjustment system; anti-load disturbance of the dynamic response slow.

Voltage chopper control means keeping $\theta_{\text {on }}$ and $\theta_{\text {off }}$ unchanged, the power switching devices operate in pulse-width modulation (PWM) mode. Keep the pulse period T is fixed, simply adjust the duty cycle of the PWM waveform, thereby adjusting the size of the voltage across the winding, which cause changes in winding phase current to achieve the regulation of motor speed[1-2]. The control method according to the freewheeling ways can be divided into single-tube and double tube Chopper, Taking into account the system efficiency factors, most takes a single tube Chopper. The control main features include: suitable for both high-speed operation and low-speed operation; its resistance to load disturbance of the dynamic response is fast; when running at low speed that is able to produce large torque ripple.

\subsection{Torque Distribution Strategy}

Torque distribution strategy refers that by defining the torque share function (TSF), electromagnetic torque component of corresponding phase current can be distributed reasonably to ensure each phase resultant torque being at a constant value. Accordingly the phase current command value can be introduced and combined with appropriate control strategies to achieve low torque ripple control.

Reference [4] proposed an optimized solution based on conventional torque distribution strategy to maximize the torque / ampere ratio within the allowable error 
range of torque ripple, adjusting the opening angle $\theta_{\text {on }}$ SRM and off angle $\theta_{\text {off }}$ on line. Under the premise of guaranteed output torque, lower the winding phase current, so as to achieve the purpose of optimization. By the establishment and comparison of regular programs and the optimized models, it is known that the Torque / ampere ratio is optimized while improving the efficiency of the system.

For the SRM torque ripple, Reference [5] adopts the torque distribution strategy based controller to obtain the desired torque of each phase, and then synthesize the constant torque through each phase, enabling the effective suppression of torque ripple.

Reference [6] combines the current torque distribution and current to achieve effective inhibition of the torque ripple. To some extent the purpose has been achieved by this method, but the select of the torque share function (TSF) ignored the necessary physical constraints.

In order to extremely minimize the torque error, reference [7] analyzes the optimization by using flux linkage as optimizing variables. With discrete method, transfer the torque error minimization problem into a mathematical programming problem. Its feasibility has been proved by simulation. But the premise of the method is omit the used is to the electromagnetic coupling between winding.

Reference [8] proposed a linear torque share function (TSF). This function changes linearly during commutation, and the correspondent positions of commutating current are the same. There are a number of factors are idealized in this method, so the actual effects are not ideal.

Reference [9] conducts a more comprehensive comparison and analysis of the optimized effect of torque ripple in terms of four kinds of torque share function (TSF) from the speed range, copper loss, overlap angle and the conduction angle. The result is that how to choose torque share function (TSF) is critical.

\subsection{Intelligent Control}

Because Intelligent Control belongs to the nonlinear control in the mathematical essence and it is of strong self-learning ability and adaptive capacity, so applying the intelligent control theory to design SRM controller is one of the effective way to solve this thorny issue. Intelligent control is mainly used for off-line or on-line learning and optimization of SRM phase current waveform, with appropriate inner current control to reduce torque ripple and achieve high performance control of SRM.

\subsubsection{Fuzzy Control}

Typical application of fuzzy control is an adaptive fuzzy control strategy of minimum switch reluctance machine torque ripple proposed by Sayeed [10]. Figure 2 shows the adaptive fuzzy SRM torque control system regarding position as an input, phase current an output. Changing the membership function makes each phase break over in the most appropriate area. The initial value of the fuzzy parameter is randomly selected ,during operation is controlled by the real-time adjustments to achieve the optimum, design of the controller is not dependent on prior knowledge, Able to adapt to the motor characteristics of any changes ,it is possible to adapt the characteristics of the motor, the rotor position feedback for the error with a more strong robustness, the torque generated in the region of the maximum positive torque, increasing the torque density, to avoid the high peak current, the torque ripple is minimized. However, since this is a single-input, singleoutput fuzzy system, for a constant torque for a given signal, the weights can be changed according to online features and operating conditions of the motor, but when given the torque changes Since there is no memory function fuzzy controller, the controller cannot 
be adjusted in real time according to changes in a given coefficient of torque, the need to re-learn.

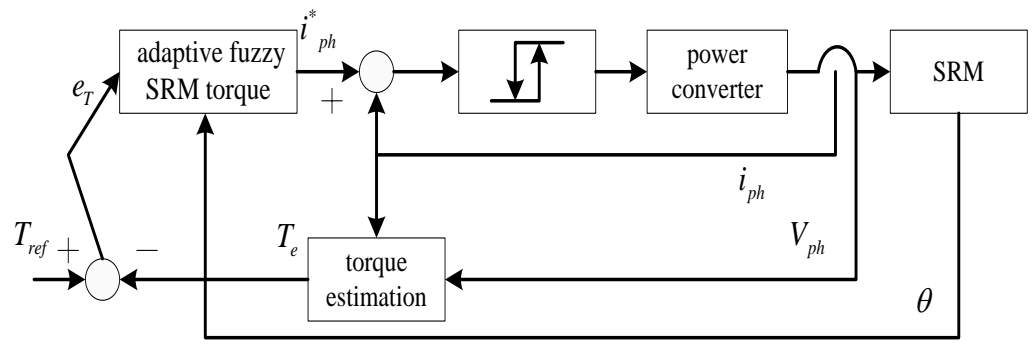

Figure 2. The Block Diagram of Adaptive Fuzzy Torque Control

According to the real-time speed, torque, position angle and the size of the current signal, Reference [11] applies fuzzy neural algorithm constantly adjusting the size of the current compensation signal to optimize the phase current waveform and then to inhibit torque ripple. Because the real-time measurement of the dynamic torque is difficult and the torque sensor is so expensive that difficult to apply this method allows real time control of the motor. Another simulation training data is obtained from the motor steadystate operation; the motor is running parameter changes will bring about change performance.

For lack of fuzzy control, fuzzy control and neural network combining the fuzzy neural network inverse model of the static torque characteristics of SRM offline learning, re-use torque distribution function in real-time on-line optimization of the desired torque needed the phase current waveform to achieve linear motor torque, decoupling, no ripple control [12].

Reference [13] through the fuzzy neural network speed controller determines the desired torque output, application distribution function to calculate the value of each phase torque command, torque-angle curve using the table to obtain the corresponding current value of each phase, and through hysteresis fast tracking current control to achieve control.

Reference [14] proposed a new method of mathematical modeling of a motor switched reluctance, based on the static inductance curve and torque-angle characteristic curve, apply the adaptive network based fuzzy inference system to the whole modeling of SRM. The fuzzy inference system consists of 5 networks, It combines the fuzzy inference with neural network organically, It realizes the formation of a simple structure 、 compact network to get the nonlinear mapping relationship of electric current、Rotor position angle 、 inductance and torque by making use of the membership function and the fuzzy rules. In the end, we can get the off-line training models of the inductance and torque.

\subsubsection{Neural Network}

Reduce torque ripple neural network-based method was first proposed by JGO Donovan [15], etc., consider the nonlinear characteristics of SRM, according to the torque of the SRM - current - the angular relationship, on a priori knowledge of motor learning. Learning to reduce the torque ripple of the motor phase current waveform capability through self-learning neural network, but the common neural network learning speed they take slow, and needs offline learning, it is difficult for real-time control of the motor.

Reference [16] applies AMN (associative memory networks) neural network online to get the motor phase current waveform optimization [16]. Inadequacies of this approach are that: the torque sensor expensive and inaccurate measurements at high speeds, and only used for training, practicality is not strong. Judging from the control block diagram, there is no torque feedback during normal operation, and phase current waveform is only 
concerned with the torque and position angle, when the actual operating conditions and learning conditions have changed, the performance is difficult to guarantee. To ensure the performance of the network, the need for torque signal under different conditions for learning, which in turn increases the complexity of the network and learning.

Reference [17] proposed to make adaptive PID control with the traditional combined to form neural network adaptive PID control strategy that is applied to nonlinear serious switched reluctance motor, which can realize high performance control of switched reluctance motor. Meanwhile, the non-linear transformation properties and a high degree of parallel processing ability of neural networks has makes it suitable for the establishment of non-linear predictive model parameters to predict. Through the prediction of the controlled system parameters can improve the dynamic response performance of the system, as shown in Fig3. This paper uses BP neural network and RBF neural network to form neural networks and neural networks NNI- respectively NNC. Neural network adaptive PID parameters will be adjusted; NNI used to create nonlinear prediction model to forecast parameters. in order to accelerate the convergence rate of learning neural network, this paper uses variable learning rate of Neural network learning algorithm, With the convergence of the learning process error rate adaptively adjust the size, which can greatly speed up the neural network convergence speed of learning and training, to further improve the system dynamic response speed .Experimental results show that the dynamic response of the system quickly, small overshoot, high steady-state accuracy, robustness, strong anti-disturbance capacity, with good control effect.

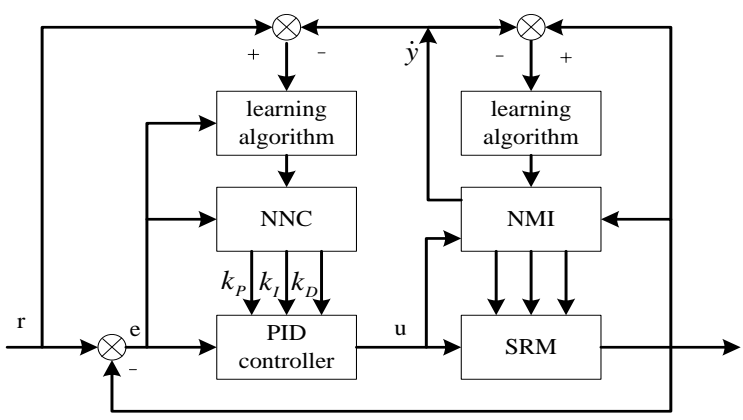

\section{Figure 3. Block Diagram of the Nonlinear Model based on RBF Neural Network}

Reference [18] proposed a switched reluctance motor instantaneous torque control method which based on radial basis function neural network. Using data generated from the SRM dynamic simulation for RBF neural network's offline training, learning to optimize current waveforms under different speed and torque, and then trained RBF network is used for torque control of the motor, the completion different speed, torque, position to the current non-linear mappings. Finally, the instantaneous current tracking control motor current tracking reference current to complete torque control of the motor, shown in Figure 4. The control method leverages the RBF neural network approximation, generalization ability, fast speed advantage; the control process is simple, and the network without online training. Experimental results show that the control strategy can effectively reduce torque ripple switched reluctance motor with high control accuracy, and which able to adapt to speed changes. 


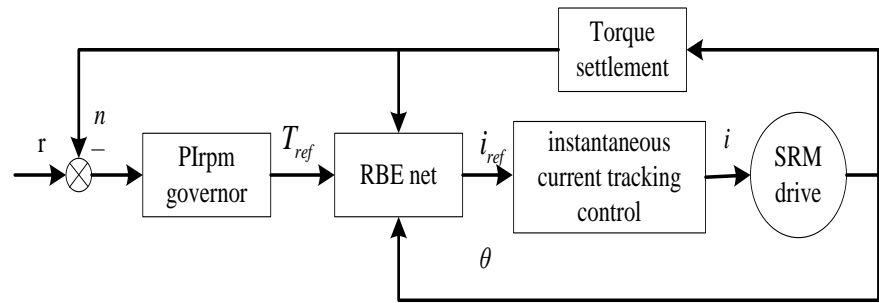

\section{Figure 4. The Block Diagram of RBF Neural Network of Instantaneous Torque Control}

Reference [19] proposed to make two-step and three-step commutation method to introduce direct instantaneous torque control, which is a new method that can either form a vibration and noise reduction, but also can reduce the torque ripple. In order to reduce the vibration period of the chopper, after each torque chopper trigger a three-step commutation method. We use three-step commutation method with the same amplitude level of jumping chopping torque level jump amplitude. Therefore, every vibration caused by torque chopper was weakening by three-step commutation method in commutation time. In addition, we determine the vibration method according to the phase. Meanwhile, the paper also gives a three-step phase method for time parameter optimization method. Experimental results demonstrate the effectiveness of the control strategy.

\subsection{Linearization Control}

Reference [20] Taking into account the SRM is coupled nonlinear multivariable systems, Differential Geometry nonlinear control methods applied SRD for the first time. SRM realized on nonlinear state feedback and linear control ,but also compensated nonlinear characteristics of SRM, Decoupling the effects of the stator current generated in the phase of the reluctance torque, In the robot trajectory tracking, SRM as a direct drive actuators achieved excellent performance, but the disadvantage is that implementation of the system needs to know all the parameters of the motor, and requires the whole state (rotor position, speed, acceleration, stator current) has testability.

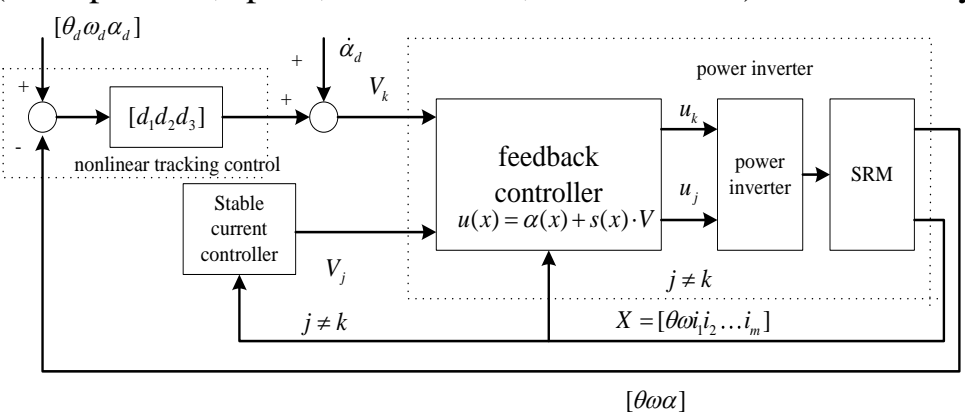

Figure 5. The Block Diagram of SRM Feedback Linearization Control

Reference [21] using a single-phase reference torque distribution function for the trapezoidal torque, Makes the original linear conduction phase torque decreases during commutation, not only use nonlinear characteristics of nonlinear compensation torque control but also inductance, so that the original nonlinear system linearization, improve system performance and reduce the torque ripple. Literature [20,21] have shown that linear control law based on feedback linearization controller than PID controller can provide better dynamic and static performance, but the feedback linearization controller purely based on linear control law is insufficient to deal with SRM model the uncertainties in the system performance is difficult to achieve the guaranteed. 
Reference [22,23] for SRM speed tracking applications, taking into account the uncertainty of the model, based on Lyapunov second method designed robust feedback linearization controller, the literature [22] for the simulation results, the literature [23] for its implementation process. By considering the system model uncertainty, and though transient SRD system, steady-state performance and robustness are improved, but its torque ripples is still large. Taylor DG, who makes the feedback linearization technique and singular perturbation techniques applied to the control of SRM, by reducing the torque ripple to achieve a high dynamic performance of the SRD, but this method is the use of the reduced model SRM and it requires that the torque - Location - current characteristics of a priori knowledge, require complex linearization and decoupling conversion circuit.

L.Ben Amor SRM power dynamic and full order parametric nonlinear model based on the mechanical dynamics, nonlinear adaptive feedback linearization control is applied to three-phase SRM [25], this approach reduces the impact of system modeling errors, to avoid the use of the online parameter estimation pre-tested, showing the position control system of high performance applications, i.e., the torque ripple is greatly reduced, with a strong inhibition of interference, and eliminates the need to measure the acceleration of the motor, without a priori knowledge of easy to implement. However, the model ignores it uses magnetic saturation effect, although this simplifies the relationship flux, inductance between the phase currents can be also brought no small errors.

Reference [26] Scott A.Bortoff have studied nonlinear adaptive control which have Low-speed, high-torque operation mode of the SRM, combined with the B-spline basis functions and Fourier sine to established of a dynamic model of SRM among electromagnetic torque, rotor position and phase current, and the dative feedback linearization controller design based on the model to achieve asymptotic trajectory tracking position, but the disadvantage is large number of parameters resulting in poor transient performance.

\subsection{Variable Structure Control}

Literature [27] the variable structure control is applied to SRD for the first time by G.S.Buja, The torque ripple regarded as interference and non-linear as gain deviation, without a priori properties of the motor to overcome the problem of the SRD. Compared with the traditional control SRD, SRD variable structure control performance is improved greatly reduce torque ripple, the system is not sensitive to parameter variations and disturbances, the control strategy is easy to achieve. But it SRD work on the magnetic properties of the linear region SRM premise ignores the influence of magnetic saturation and phase coupling. Tzu-Shien Chuang is applied dc side current-feedback design approximate sliding mode power control (as the system inner), while sliding mode speed with feed forward control with integral compensation for speed outer ring, the variable structure control theory SRM, get the ideal robust performance [28]. 


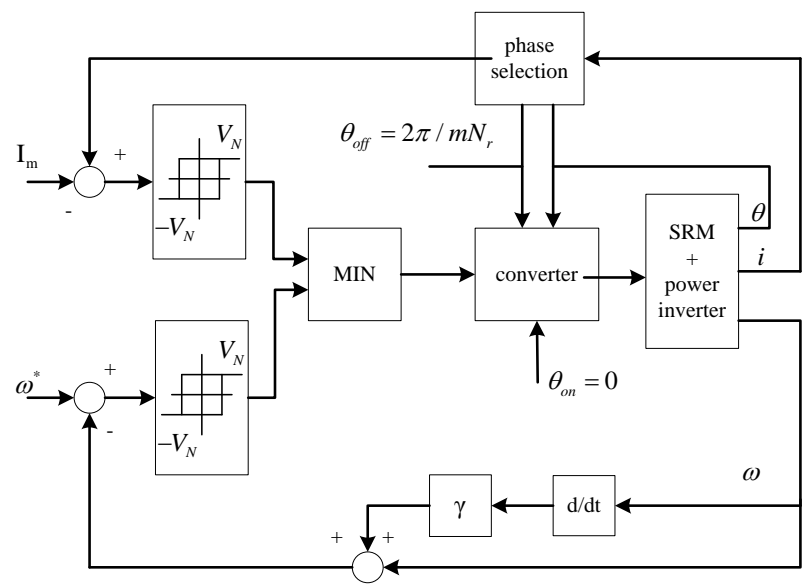

Figure 6. The Block Diagram of SRM Variable Structure Control

Reference [29] Application of Fuzzy Neural Network for SRM static torque characteristics of inverse model in offline learning, after the study, based on the torque distribution function, real-time online optimization of phase current waveform desired torque needed, While introducing equivalent Sliding Mode Variable Structure Control Theory design for SRM current controller. Simulation results show that the model of SRM motor torque current inverse controller based on sliding mode control strategy can effectively decoupling, but also compensation and offset SRM of nonlinear torque ripple characteristics, which achieve linear switched reluctance motor torque, decoupling, no ripple control.

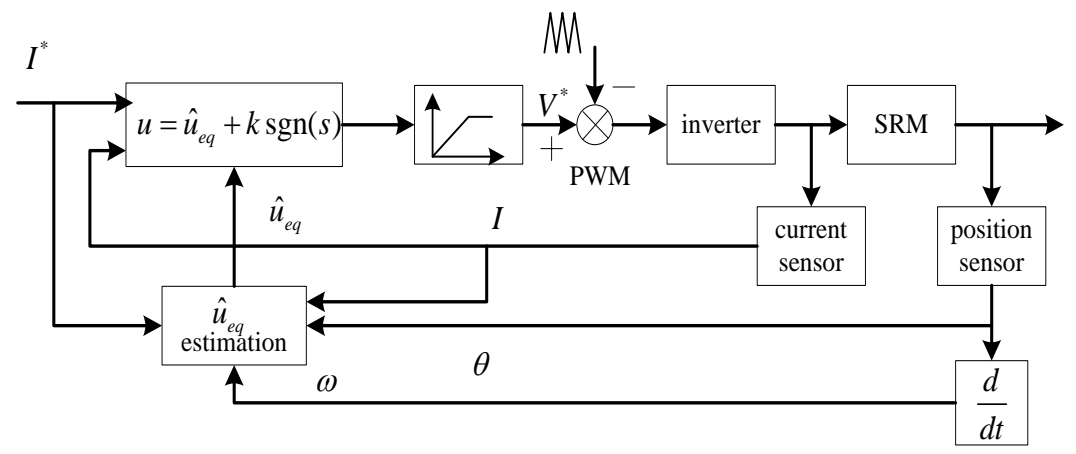

Figure 7. The Block Diagram of SRM Sliding Mode Current Controller

\subsection{Iterative Learning Control}

Reference [30] first proposed the iterative learning control is applied to the control of SRM and the first use of iterative learning control to learn phase current waveform to reduce the torque ripple of SRM, which provides a good idea for the follow-up study.

Reference [31] introduces the feed forward torque compensator and current controller, which based on iterative learning control. Feed forward compensator according to the difference between the desired torque and the actual torque, which adjust winding current constantly and minimize the error between output and desired torque, finally, get the winding current waveform that has been optimized.

Due to the application of iterative learning control was restricted by iterative cycle. So that will reduce the performance of the system transients. Reference [32] proposed the measure of Switched Reluctance Motor Direct instantaneous torque control that combine Sliding Mode Variable Structure with Iterative Learning, When the transient time control the torque of motor by a slider variable structure and steady state when using iterative 
learning to adjust and compensate, which achieve better control effect. In short, iterative learning-based approach does not need to measure the magnetic properties of the motor and the accuracy of the motor model less demanding. But for the motor operating conditions have higher requirements.

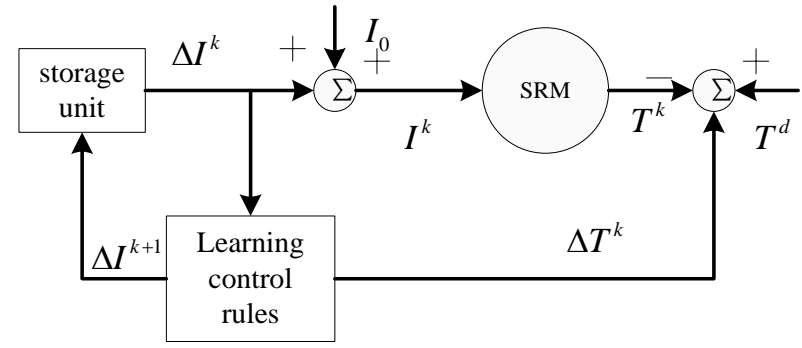

\section{Figure 8. The Block Diagram of Iterative Learning Control}

Reference [33] proposed an iterative learning control method to effectively suppress torque compensation SRM torque ripple, which is based on linear inductance model, firstly, initialize the iterative learning system output that is a given phase currents at different locations. By the measure of torque feedback and the iterative learning adjust the different positions of each phase winding current set point and adjustment learning gain by the model of nonlinear inductance to achieve the goal of accelerating the convergence rate. This paper Modeling and Simulation for this method the results show that torque compensation iterative learning control method has high accuracy and fast convergence, which can effectively reduce the SRM torque ripple characteristics.

\subsection{Internal Model Control}

Reference[34] for the first time that the model control of nonlinear systems applied to four-phase SRM torque control system, which is mainly composed of four parts: the actual SRM motor and power converter, SRM motor model, filters and nonlinear IMC controller. The target of SRM rotor position $\theta$ and output phase current $I^{P}=\left(i_{1}^{P}, i_{2}^{P}, i_{3}^{P}, i_{4}^{P}\right)$, thereby obtaining the actual electromagnetic torque and the actual speed $\omega$, and the rotor position and speed are feedback directly to the SRM model and nonlinear internal model controller. SRM model and the actual motor of SRM run in parallel, it outputs the electromagnetic torque and phase current $I^{M}=\left(i_{1}^{M}, i_{2}^{M}, i_{3}^{M}, i_{4}^{M}\right)$, phase current $I^{M}$ feedback directly to the nonlinear internal model controller. Electromagnetic torque $T_{e}^{P}$ generated by the motor and the actual shutdown phase residual current $(\mathrm{j} \neq \mathrm{k} 1, \mathrm{j} \neq \mathrm{k} 2, \mathrm{j} \in\{1, \ldots, 4\})$ was subtracted from the output of corresponding amount of model, the error as a feedback signal.

Due to factors of internal model control structure, the system model requires low, this means that is able to eliminate the steady state error without integrator, ensure that the controlled object output converges to the given value. And internal model control of nonlinear system combines the simplicity of the nonlinear feedback linearization technique and internal model control structure of robustness, which System not only to the model mismatch, parameters and various uncertainties interference has strong robustness, eliminate the influence of the uncertainty, and can effectively compensate the nonlinear characteristics of controlled object .Therefore, the system achieved a good performance, not only small torque ripple, robustness, no static error, with high dynamic characteristics, but also easy to implement. 


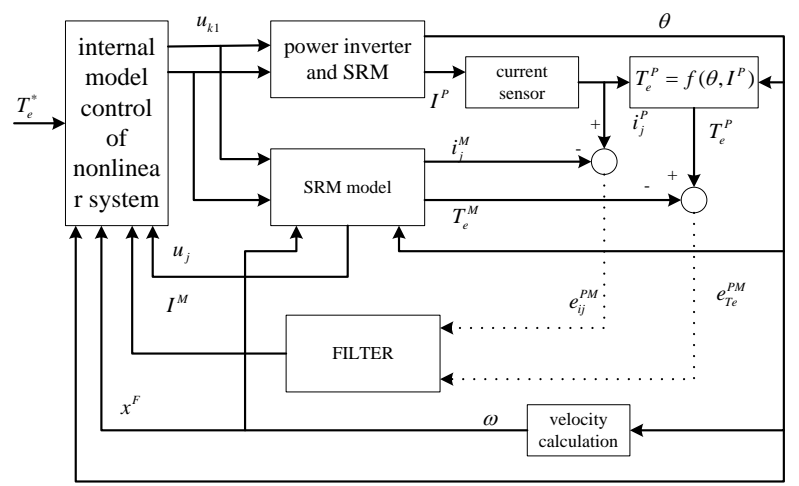

Figure 9. The Block Diagram of SRM Internal Model Control

\subsection{Other Control Methods}

Reference [35] proposed a balanced view of commutation that defined to produce the same torque at a critical angle $\theta_{c}^{\lambda}$ between adjacent two phases in the same of flux ,in the vicinity of the critical angle is calculated to obtain the minimum working point of the flux, which is the secondary objective optimized after optimization of the minimum torque ripple, voltage saturation can be avoided at a low magnetic chain working point .Only the optimal torque distribution function requires offline calculations, robustness decline , model cannot be modified, and storage memory allocation functions required torque is too large.

Reference [36] proposed in process of commutation that torque ripple minimum as the main target, which combine with the torque controller proposed a commutation strategy. At the beginning of the phase to the conduction, phase winding with zero voltage and then add the largest negative voltage to demagnetization, while measured the original residual current of the conduction phase and estimated torque. Total reference torque minus the torque generated by the residual current of original conduction phase, that is the beginning of the conduction phase of the desired torque. After this desired torque converter for the current command, we sent hysteresis controller to achieve current loop. This approach is not based on pre-calculated current or flux waveform, but with minimal torque ripple, high efficiency objectives, considering the actual torque of other phase in real time, improving the robustness of the system. However, Zero voltage width is a function of the motor speed with the speed of change in the width of the zero voltage should be adjusted accordingly.

Reference [37] proposed a model based on the magnetic chain, used in a model of cascade control including feed forward nonlinear torque compensation device and flux controllers. This system replaces the direct drive robot trajectory tracking applications. Two optimal algorithms ensures minimal torque ripple in the primary goal of optimizing reach secondary target. Two secondary optimization goal to make resistive losses relative to the minimum and minimum voltage requirements. Low voltage magnetic chain optimization will create unnecessary copper consumption curve. When high speed does not need minimum phase voltage, but it can avoid the phase voltage saturation, beyond the scope of power supply. Motor model decoupling position determines the location of items and flux decisions items.

Reference [38] introduces a method to control the motor flux directly rather than control the motor phase current or torque. Genetic algorithm is applied to the torque constant flux control, the control block diagram shown in Figure 5 .Compared with the direct current control, with a fast dynamic response, this method is ideal for digital control, but this method requires accurate information on motor characteristics and rotor position. 


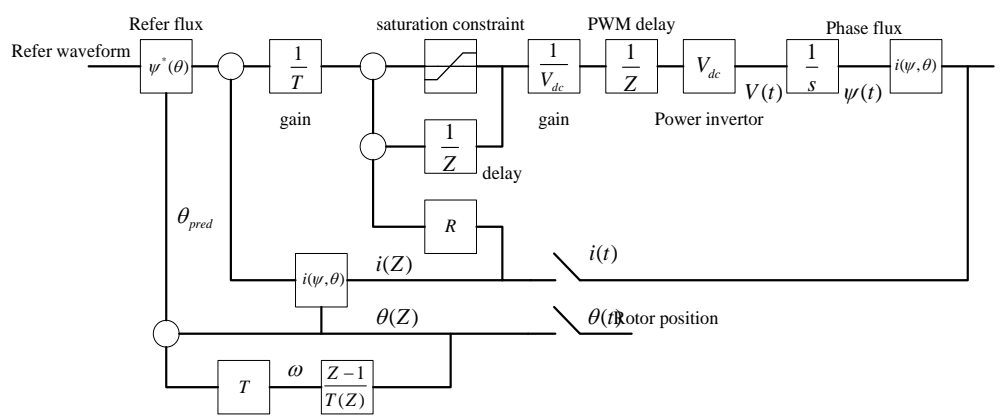

Figure 10. The Block Diagram of the Flux Linkage Controller

Reference [39] proposed a self-learning method with which a series of static and dynamic test data can be produced without load. In this way, optimal current of each phase can be obtained on line to meet the need of total torque reference. The algorithm is based on reducing the copper loss in overlaps of phase.

Reference [40] proposed a similar approach by adding a voltage feedback to the part of the current controller to increase control bandwidth.

Reference [41] proposed a direct instantaneous torque control of switched reluctance motor based on four-level power conversion circuit method. Since the conventional rising and falling of the excitation current is relatively slow, so that the efficiency and dynamic performance of the system is reduced. The four-level power conversion circuit because it can provide high voltage to the switched reluctance motor, making the excitation current rise and fall time required to reduce the proposed method based on SRM inductance curve, the rotor position is divided into three intervals, and each interval using different torque hysteresis loop control method to obtain the status of each phase switching torque hysteresis controller input comparison value command torque and instantaneous output torque.

Reference [42] proposed a function of position by the voltage and current curves of the parameterization. Parameterization suppressing the torque ripple can meet a lot of optimization criteria, such as the power supply voltage is reduced, the ripple is reduced more than the base speed, when the single-phase reduction control and the like.

\section{Conclusions}

Although the SRD system has many advantages, the obvious electromagnetic noise and torque ripple hindered SRD system being widely used in many cases. So the study on controlling Switched Reluctance Motor Torque Ripple is of great importance. With the development of various intelligent control theories, there have achieved gratifying results in the field of controlling switched reluctance motor torque ripple and there are progress in power electronics technology, digital signal processing and other advanced technology , which undoubtedly provide hardware support for advanced control strategies and promote the theoretical research of SRM control.

\section{References}

[1] H. X. Wu, "Switch reluctance motor theory and control technology", Beijing: Chinese Power Press, (2010).

[2] J. H. Wu, "Design and application of switched reluctance motor", Beijing: Machinery Industry Press, (2000).

[3] Q. H. Zhan, "Switched reluctance motor", Wuhan: Huazhong University of Science and Technology Press, (1992).

[4] B. L. Zhang, Y. W. Qi and G. S. Xu, "Switched reluctance motor torque distribution Strategy optimization", Journal of HeFei University of Technology, (2012), no. 12, vol. 35, pp. 1615-1619. 
[5] Z. L. Shi, Y. S. Huang and X. Chen, "Research on control system of Switched Reluctance Motor Based on torque distribution strategy", Coal mine machinery, vol. 31, no. 12, (2010), pp. 59-61.

[6] B. Yang, J. Y. Cao and Y. P. Chen, "A new method to reduce the torque ripple of switched reluctance motor", Small and medium sized motor, vol. 28, no. 4, (2001), pp. 11-15.

[7] J. Y. Cao, Z. D. Zhou and Y. P. Chen, "A new method of switch reluctance motor torque control", Proceedings of the CSEE, (2005).

[8] D. S. Schramm, B. S. Williams and T. C. Green, "Torque Ripple Reduction of Switched Reluctance Motors by Phase Current Opitimal Profiling", Proceedings of IEEE PESC, (1992).

[9] X. D. Xue, K. W. E. Cheng and S. L. Ho, "Optimization and Evaluation of Torque-sharing Functions for Torque Ripple Minimization in Switched Reluctance Motor Drives", IEEE Transaction on Power Electronics, vol. 24, no. 9, (2009), pp. 2076-2090.

[10] S. Mir, M. E. Elbuluk and I. Husain, "Torque-rippleMinimization in Switched Reluctance Motors Using Adaptive Fuzzy Control”, IEEE Transactions on Industry Applications, vol. 35, no. 2, (1999), pp. 461468.

[11] L. O. A. P. Henriques, L. G. B. Rolim and W. I. Suemitsu, "Torque Ripple Minimization in a Switched Reluctance Drive by Neuro-fuzzy Compensation", IEEE Transactions on magnetics, vol. 36, no. 5, (2000), pp. 3592-3594.

[12] H. T. Zheng, X. Chen and J. P. Jiang, "Fuzzy high performance torque switch reluctance motor control based on Neural Network", Control theory and Applications, vol. 20, no. 4, (2003), pp. 541-546.

[13] Z. Q. Fan and P. Wang, "Methods of inhibiting intelligent torque ripple of switched reluctance motor", Micromotor, vol. 28, no. 2, (2000), pp. 28-30.

[14] D. L. Liang, W. Ding and Z. M. Yu, "Modeling for Switched Reluctance Motor Based on adaptive network based fuzzy inference system", Proceedings of the CSEE, (2008).

[15] J. G. O'Donavan, P. J. Roche and R. C. Kavanagh, "Neural Network Based Torque Ripple Minimization in a Switched Reluctance Motor", IECON, (1994), pp. 1226-1231.

[16] D. S. Reay, T. C. Green and B. W. Williams, "Application of Associative Memory Neural Networks to $t$ he Control of a Switched Reluctance Motor", IECON, vol. 1, (1993), pp. 200-206.

[17] C. L. Xia and J. Xiu, "Switched reluctance motor adaptive PID prediction model of nonlinear control based on RBF neural network", Proceedings of the CSEE, (2007).

[18] C. L. Xia, Z. R. Chen and B. Li, "Switched reluctance motor instantaneous torque control based on RBF neural network", Proceedings of the CSEE, (2006).

[19] J. B. Sun, Q. H. Zhan and S. H. Wang, "Noise and vibration control of switched reluctance motor and low torque ripple control strategy", Proceedings of the CSEE, (2008).

[20] M. I. Spong, R. Marino, S. M. Peresada and D. G. Taylor, "Feedback Linearizing Control of Switched Reluctance Motors", IEEE Trans. Automatic Control, vol. 232, no. 5, (1987), pp. 371379.

[21] H. Cailleux, B. Le Pioufle and B. Multon, "Comparison of Control Strategies to Minimize the Torque Ripple of a Switched Reluctance Mach ine", Electric Machines and Power Systems, vol. 25, (1997), pp. 1103-1118.

[22] S. K. Panda and P. K. Dash, "Application of Nonlinear Control to Switched Reluctance Motors: a Feedback Linearisation Approach", IEE Proc. Electr. Power Appl., (1996).

[23] Y. H. Qing, S. K. Panda and L. Y. Chii, "Experimental Investigation of Feedback Linearization Controller for S itched Reluctance Motor", Conf. Rec. IEEE Power Electronics Specialists Conf., (1996).

[24] D. G. Taylor, M. J. Woolley and M. Ilic, "Design and Implementation of a Switched ReluctanceMotor", Proc. 17th Symp., Incremental Motion Control Systems and Devices, Champain, IL, (1988).

[25] L. B. Amor, L. A. Dessaint, O. Akhrif and G. Olivier, "Adaptive Feedback Linearization for Position Control of a Switched Reluctance Motor: A nalysis and Simulation", International Journal of Adaptive Control and Signal Processing, (1993).

[26] S. A Bortoff, R. R. Kohan and R. Milman, "Adaptive Control of Variable Reluctance Motors: a Spline Function Approach”, IEEE Trans. Industrial Electronics, vol. 45, no. 3, (1998), pp. 433-444.

[27] G. S. Buja, R. Menis and M. I. Valla, "Variable Structure Control of an SRM Drive", IEEE Trans. Industrial Electronics, vol. 40, no. 1, (1993), pp. 56-66.

[28] T. S. Chuang and C. Pollock, "Robust Speed Control of a Switched Reluctance Vector Drive Using Variable Structure Approach”, IEEE Trans. Industrial Electronics, vol. 44, no. 6, (1997), pp. 800-808

[29] H. T. Zheng and J. P. Jiang, "Switched reluctance motor high performance torque control strategy research", Transactions of China Electrothchnical Society, no. 9, (2005), pp. 25-28.

[30] N. C. Sahoo, J. X. Xu and S. K. Panda, "Determination of Current Waveforms for Torque Ripple Minimization in Switched Reluctance Motors Using Iterative Learning: an Investigation", Electric Power Applications, IEE Proceedings, (1999).

[31] N. C. Sahoo, J. X. Xu and S. K. Panda, "Low Torque Ripple Control of Switched Reluctance Motors Using Iterative Learning", IEEE Transactions on Energy Conversion, vol. 16, no. 4, (2001), pp. 318-326.

[32] N. C. Sahoo, S. K. Panda and J. X. Xu, "Iterative Learning Control Based Direct Instantaneous Torque Control of Switched Reluctance Motors", 35th Annual IEEE Power Electronics Specialists Conference, (2004). 
[33] H. M. Li, Z. Z. Zhang and Z. J. Li, "Iterative learning control for reduction of a small power switched reluctance motor torque ripple", Transactions of China Electrothchnical Society, vol. 21, no. 10, (2006), pp. 67-70.

[34] B. M. Ge, "Novel control strategies for AC drive system", PhD thesis, Hangzhou: Zhejiang University, (2000).

[35] P.C. Kjaer, J. J. Gribble and T. J. E. Miller, "High-grade control of switched reluctance machines", IEEE Transactions, vol. 33, (1997), pp. 1585-1593.

[36] K. Russa, I. Husain and M. Elbuluk, "Torque ripple minimization in switched reluctance machines over a wide speed range", IEEE Trans. Ind. Applicat., vol. 34, (1998), pp. 1105-1112.

[37] F. Filicori, G. C. Lo Bianco and A. Tonielli, "Modeling and control strategies for a variable reluctance direct-drive motor", IEEE Trans. Ind. Electron., vol. 40, (1993), pp. 105-115.

[38] P. G. Barrass and B. C. Mecrow, "Flux and torque control of switched reluctance machines", Proc. IEE -Elect. Power Applicat., (1998)

[39] R. C. Kavanagh, J. M. D. Murphy and M. G. Egan, "Torque ripple minimization in switched reluctance drives using self learning techniques”, Proc. IEEE IECON, (1991).

[40] C. Rochford, R. C. Kavanagh, M. G. Egan and J. M. D. Murphy, "Development of smooth torque in switched reluctance motors using selflearning techniques", Proc. IEE Conf., (1993).

[41] Z. G. Li, Y. j. Wei, Z. Z. Kan and H. H. Qi, "Switched reluctance motor instantaneous torque control of four level converter based", Transactions of China Electrothchnical Society, vol. 22, no. 80, (2007), pp. 144- 149.

[42] A. M. Stankovic, G. Tadmor and Z. J. Coric, "Low torque ripple control of current-fed switched reluctance motors", Conf. Rec. IEEE-IAS Annu. Meeting, (1996). 